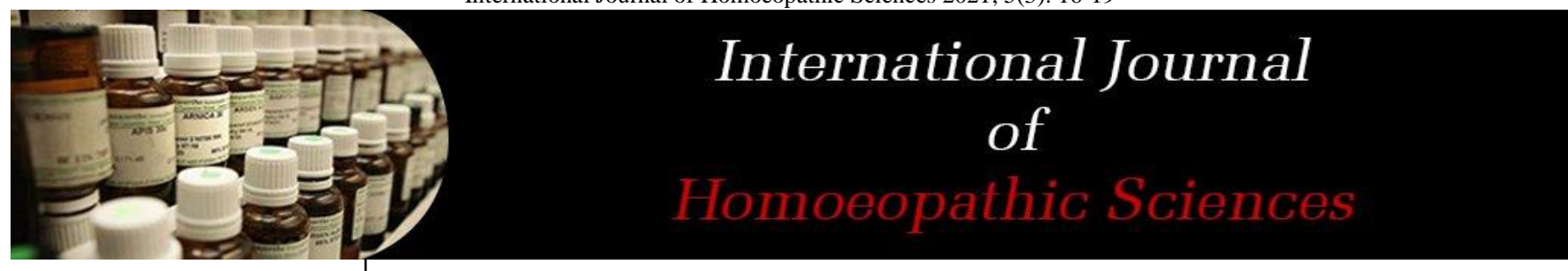

E-ISSN: 2616-4493 P-ISSN: 2616-4485 www.homoeopathicjournal.com IJHS 2021; 5(3): 16-19

Received: 13-05-2021

Accepted: 17-06-2021

Dr. Biplab Kumar Das Medical Officer (RBSK), ONDA BPHC, Bankura, West Bengal, India

Dr. Ajoy Kumar Mondal Medical Officer (RBSK) Balli Jagacha Rural Hospital, Jagadishpur, Kona, Howrah, West Bengal, India
Corresponding Author: Dr. Biplab Kumar Das Medical Officer (RBSK) ONDA BPHC, Bankura, West Bengal, India

\section{A case report of oral mucous cyst and homoeopathy}

\section{Dr. Biplab Kumar Das and Dr. Ajoy Kumar Mondal}

DOI: https://doi.org/10.33545/26164485.2021.v5.i3a.397

\section{Abstract}

Mucus cysts are very common in oral cavity. All ages groups are equally effected, it's may be seen in child and also old age. Most frequently is seen in the lower lip. Most probable cause is trauma or habit of lip biting. Diagnosis is mainly established clinically due to its pathognomonic presentation. In allopathic point of view is surgical excision of the lesion usually treatment of choice.

Case summary: This is a case the patient was suffering from oral mucosal cyst last one month having a small, painless, movable, and soft, in lower lip. The patients were prescribed indicated constitutional Homoeopathic medicines. Individualised homoeopathic medicine Nitric Acid was prescribed in centesimal potency which showed a positive role in the treatment of lower lip mucous cyst. Within two and half months inner side of lower lip mucous cyst was annihilated.

Keywords: lower lip, mucous cyst, homoeopathy, nitric acid

\section{Introduction}

This cyst usually develops due to obstruction of the duct of a small mucous secreting gland. So this cyst may occur anywhere on the inner surface of the lips, cheek and the mouth where these mucous secreting glands are present. It is more on lower lip and in the buccal mucous membrane of the cheek at level of the bite of the teeth. The cyst may occur at any age. This cyst is usually spherical with smooth surface and consistency varies from soft to hard according to the tension of fluid inside the cyst. Fluctuation and transillumination tests are positive when the cysts are large enough. This cyst is neither fixed to the overlying mucous membrane, nor fixed to the deeper structures. The regional lymph nodes are not enlarged ${ }^{[1]}$. Lower lip is the most common site of occurrence of these lesions in the oral cavity and most probable cause is trauma or habit of lip biting ${ }^{[17]}$. Mucus cysts of minor salivary glands produce pinkish, bluish, or yellowish, globular, soft swellings up to $1.5 \mathrm{~cm}$ in diameter on the inner aspect of lips or cheeks ${ }^{[16]}$. The exact mechanism behind formation of the mucocele is not known. Mucoceles have been classified as- an extravasation mucocele or a retention mucocele. The extravasation type is far more common than the retention type. Sometime exhibiting both phenomena in same case ${ }^{[2]}$. The most common location of the extravasation mucocele is the lower lip. Mucoceles most probably affect young patients, but can affect all the age groups. The treatment of choice is surgical excision of the mucocele ${ }^{[18]}$. Reports show that most mucoceles occurred in the second and third decade of life. Few cases have been reported in newborns ${ }^{[4,5]}$.

Clinically they are characterized by single or multiple, soft, fluctuant nodule, ranging from the normal color of the oral mucosa to deep blue. It affects at any age and is equally present in both sexes with highest incidence in second decade of life ${ }^{[15]}$.

\section{Case study}

\section{Patient information}

A 42 year old male came to my clinic on $21^{\text {th }}$ Jan 2021, with complaints of a painless small swelling inner side of lower lip for last 1 month which was gradually increasing on size.

\section{History of present complaint}

Patient presented with swelling inner side of lower lip for last 1 month which was gradually increasing on size. The swelling was small painless, no history of trauma. No treatment taken.

\section{Past history}

In past he suffered from chicken pox at the age 20 yrs., treated homoeopathically with recovery. 


\section{Family history}

Father was suffering DM, Hypertension, mother was suffering from Arthritis. Elder brother was suffering from arthritis.

\section{Physical generals}

Patient was thirsty, appetite was good. Desire fat food, sour, acid and salt. Sweating was offensive. Sleep was normal. Patient was constipated. Thermally he was chilly.

\section{Mental generals}

Weakness of memory, aversion to company.

\section{General survey}

Patient was well oriented, alert and cooperative. Clinically no anaemia, cyanosis, oedema, jaundice or clubbing are detected. His weight was about $64 \mathrm{~kg}$.

\section{On examination}

Soft cystic swelling inner side of lower lip which was no pain on pressure.

\section{Provisional diagnosis \\ Oral mucosal cyst}

\section{Justification of diagnosis \\ Symptomatic}

\section{Analysis and evaluation of the case}

After analysis the symptoms of the case, the characteristic mental generals, physical generals and particular symptoms for formation of the totality. Aversion to company, weakness of memory. Desire for fat food, sour, acid and salt.

Patient was thirst lees, constipated, offensive sweat, chilly patient were considered as the mental and physical generals. A particular symptom was Soft cystic swelling inner side of lower lip.

\section{Miasmatic analysis}

Analysis is showing picture of mixed-miasmatic condition with sycosis ${ }^{[8]}$ predominant.

\section{Reportorial analysis}

Considering the above symptomatology, Kent Repertory was preferred. After repertorisation (Table 1 and Figure 1), many medicines were competing each other, namely Nitric acid, Sulph., Phos., Con., Hep., Lyco etc. Where maximum number of symptoms was covered by Nitric Acid and obtained was also highest rank i.e. $20^{[14]}$. This result was also further cross matching with repertories having the rubric of 'oral cyst'. In Hering's guiding symptoms repertory - mouth, tumors: spongy, painless, size of a marble, on inner side of right lower lip, near corner of mouth, with a streak down neck, I Nitr. Ac. ${ }^{[12]}$. In Phatak's Repertory rubric-Cysts-Nitric-ac and Mouth, Tumours: Calc; Lyco; Nitric-ac. And Painles: Calc; Nitric-ac. ${ }^{[11]}$. After final consultation of Materia Medica Nitric acid was prescribed ${ }^{[9,13]}$.

Table 1: Symptoms Rubrics Page No. ${ }^{[14]}$

\begin{tabular}{|c|c|c|}
\hline Symptoms & Rubrics & Page No. \\
\hline Aversion to company & Company, aversion to & 12 \\
\hline Weakness of memory & Memory, weakness of & 64 \\
\hline Desire fat food & Desires, fat & 485 \\
\hline Desire salt & Desires, salt things & 486 \\
\hline Desire sour and acid & Desires, sour, acid & 486 \\
\hline Patient was thirst less & Thirstless & 530 \\
\hline Constipated & Constipation & 606 \\
\hline Offensive sweat & Perspiration, ODOR, offensive & 1298 \\
\hline Chilly patient & Heat, vital, lack of & 1366 \\
\hline Soft cystic swelling inner side of lower lip & Tumors & 427 \\
\hline
\end{tabular}

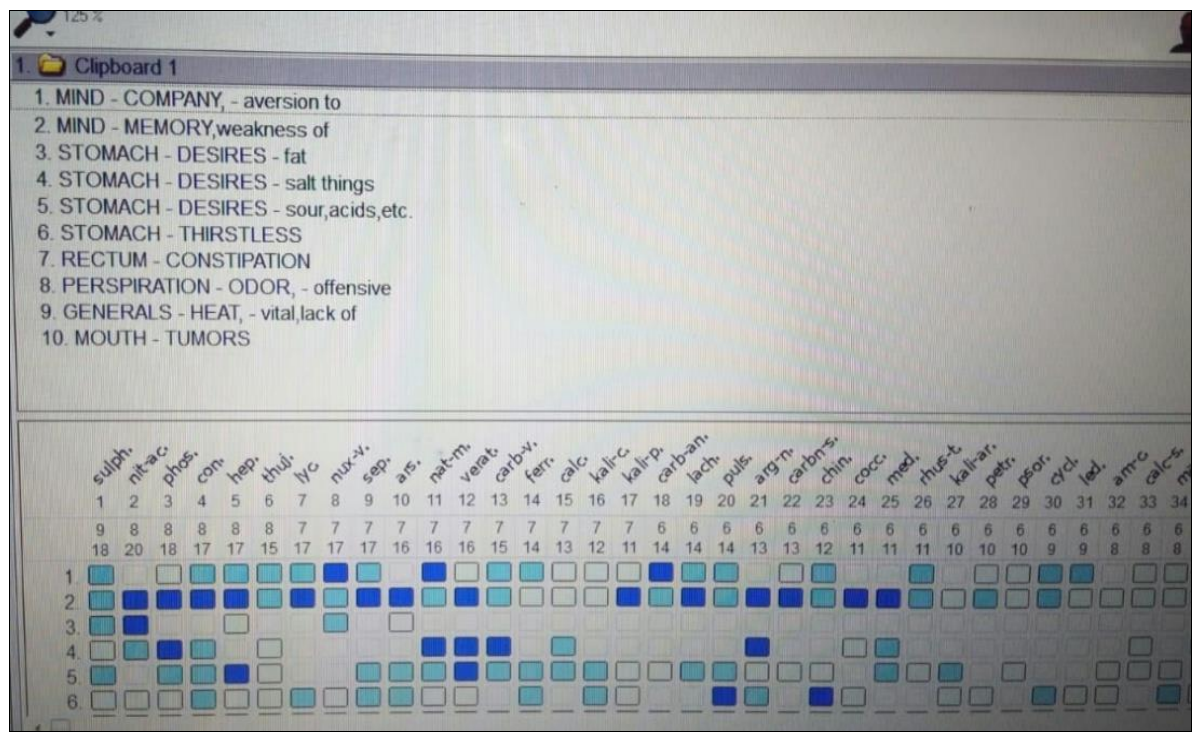

Fig 1: Repertorisation chart 


\section{Remedy with potency selection and administration}

Nitric Acid 30 was prescribed on $21^{\text {st }}$ January 2021 in 10 no globules, two dose taken OD AC in empty stomach and placebo globule taken thereafter same manner for 21 days.
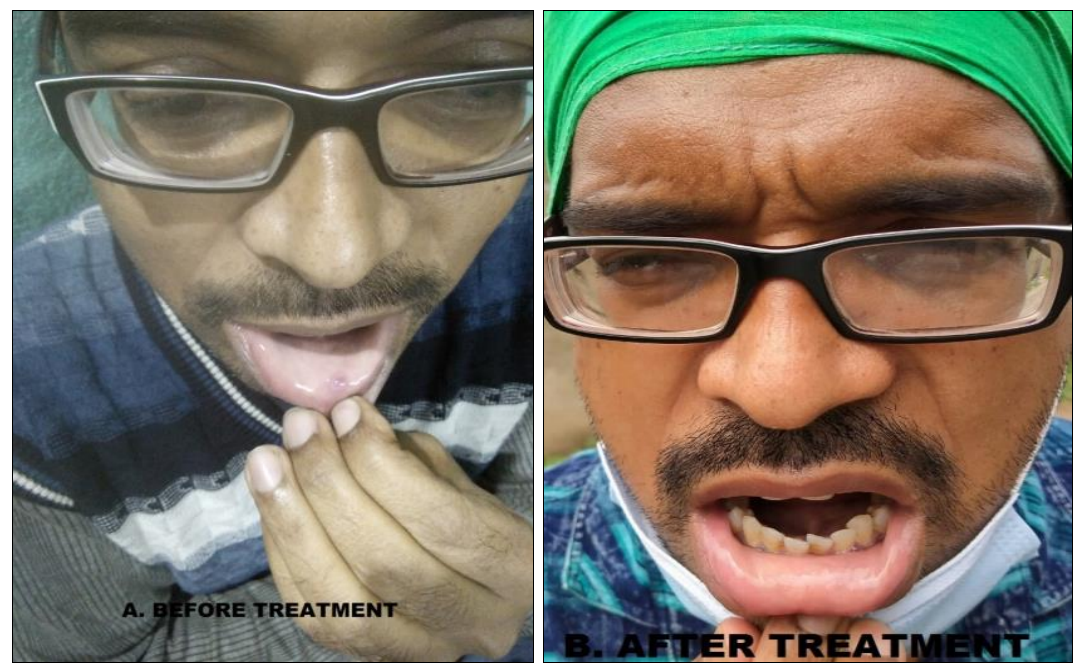

Fig 2: Before and after treatment results

Table 2: Treatment chronology

\begin{tabular}{|c|c|c|}
\hline Date & Observation & Prescription and advice \\
\hline $12 / 02 / 2021$ & $\begin{array}{c}\text { Swelling reduced in size; with patient not clear regular } \\
\text { bowel movement, but offensiveness of sweat present. }\end{array}$ & Placebo was prescribed for 21 days \\
\hline $07 / 03 / 2021$ & Size of cyst reduced, patient no other complain. & Placebo was prescribed for 21 days \\
\hline $01 / 04 / 2021$ & $\begin{array}{c}\text { The cystic swelling totally disappeared; no other } \\
\text { complains and feels better in all respect. }\end{array}$ & No treatment. \\
\hline
\end{tabular}

\section{Discussion}

In this case Nitric Acid 30C potencies was prescribed, which covered the totality of symptoms of the patient and it has shown positive results, swelling reduced gradually and associated with overall health improved, regular bowel movement, sweat offensive less. In this case, the total score of outcome as per Modified Naranjo Criteria was 8, which was close to the maximum score of 13 . In modern medicine surgery is choice of treatment, but after surgery most common complication was recurrence of cyst. Certain documentation is available regarding oral mucous cyst. A case of an 8 year old girl is presented here who presented with lingual mucocele and was treated with individualized homoeopathic medicine Calcarea carbonica. The swelling disappeared within one month of treatment with general improvement of the patient ${ }^{[6]}$. Another was case of a female child with a painless, cystic swelling in the right side of the floor of the mouth of 3-month duration and another smaller painless cystic swelling on the inner side of the right lower lip. Clinical diagnosis reveals the cystic mass in the floor of the mouth as a simple ranula. After individualising the case, homoeopathic medicine Ambra grisea 30 was prescribed, and within 2-3 months, ranula obliterated. The other smaller cystic swelling also disappeared simultaneously ${ }^{[7]}$. This is by far most important variety of local maladies and the approach of Homoeopathy is entirely different here from those of the other schools of medicine. Cyst is a local maladies. A tumour or cyst is undoubtedly amenable to constitutional homoeopathic treatment but a stage may come when the growth may assume such a large size that it may cause troublesome pressure symptoms or threatening malinency may supervene endangering the life of the patient. In such cases surgical removal of the growth followed by constitutional antimiasmatic medicine should be the method of choice ${ }^{[10]}$.

Table 3: Assessment by modified Naranjo criteria score

\begin{tabular}{|c|c|c|c|}
\hline Item & Yes & No & $\begin{array}{c}\text { Not sure/Not } \\
\text { applied }\end{array}$ \\
\hline $\begin{array}{c}\text { Was there an improvement in the main symptom or condition, for which the homoeopathic medicine was } \\
\text { prescribed? }\end{array}$ & +2 & & \\
\hline Did the clinical improvement occur within a plausible time frame relative to the drug intake? & +1 & & \\
\hline Was there an initial aggravation of symptom? (Need to define in glossary) & & 0 & \\
\hline $\begin{array}{l}\text { Did the effect encompass more than the main symptom or condition, i.e., were other symptoms ultimately } \\
\text { improved or changed? }\end{array}$ & +1 & & \\
\hline Did overall well-being improve? (Suggest using validated scale) & +1 & & \\
\hline $\begin{array}{c}\text { Direction of cure: Did some symptoms improve in the opposite order of the development of symptoms of the } \\
\text { disease? }\end{array}$ & - & 0 & \\
\hline Direction of cure: Did at least two of the following aspects apply to the order of improvement of symptoms: & & & \\
\hline $\begin{array}{l}\text { - From organs of more importance to those of less importance } \\
\text { - } \quad \text { From deeper to more superficial aspects of the individual } \\
\text { - From the top downwards }\end{array}$ & - & & 0 \\
\hline
\end{tabular}




\begin{tabular}{|c|c|c|}
\hline $\begin{array}{c}\text { Did 'old symptoms' (defined as non-seasonal and non-cyclical symptoms that were previously thought to have } \\
\text { resolved) reappear temporarily during the course of improvement? }\end{array}$ & & 0 \\
\hline $\begin{array}{c}\text { Are there alternate causes (other than the medicine) that - with a high probability - could have caused the } \\
\text { improvement? (consider known course of disease, other forms of treatment and other clinically relevant } \\
\text { interventions) }\end{array}$ & +1 \\
\hline Was the health improvement confirmed by any objective evidence? (e.g. laboratory test, clinical observation & +2 & \\
\hline Did repeat dosing, if conducted, create similar clinical improvement? & N/A & \\
\hline
\end{tabular}

N/A: Not available

\section{Conclusion}

This case has highlighted the importance of best on symptoms similarity with individualization of the patient for a remedy selection, and not just common of symptoms of disease. The above case study along with previous documented articles provides example in the utility of homoeopathic treatment in cases of oral mucosal cyst. However, more such case studies and clinical trials are required to reproduce similar results of Homoeopathy in surgical conditions and validate the outcome. In Homoeopathic field much more clinical case studies and trials are required for such types of surgical condition.

\section{Financial support and sponsorship \\ Nil}

\section{Conflicts of interest}

None declared

\section{References}

1. Das SA. Manual on Clinical Surgery. 6th ed., Calcutta: S. Das, 13, Old Mayor's Court; Calcutta 2004, 265.

2. Arunachalam P, Thayalan D, Razak A, Abiramivaman K, Gowtham A, Rajesh A. Mucocele showing both retention and extravasation phenomenon: An eccentric case report. SRM J Res Dent Sci 2021;12(01):48-51. 10.4103/srmjrds.srmjrds_123_20.

3. RADAR 10, Archibel Homoeopathic software. Belgium.

4. Hayashida AM, Zerbinatti DC, Balducci I, Cabral LA, Almeida JD. Mucus extravasation and retention phenomena: A 24-year study. BMC Oral Health 10. Article No-15 2010. doi.org/10.1186/1472-6831-10-15.

5. Jani DR, Chawda J, Sundaragiri SK, Parmar Mucocele G. A study of 36 cases. Indian J Dent Res 2010;21(3):337-340. 10.4103/0970-9290.70793.

6. Dr. Arunava Nath, Dr. Deb Kumar Palit. Homoeopathic management of oral mucocele: Acase report. Int J Hom Sci 2020;4(1PartB):100-104.

7. Pal PP. Obliteration of ranula with homoeopathic treatment: A case report. Indian J Res Homoeopathy 2021;15(01):48-54. 10.4103/ijrh.ijrh_27_20.

8. Banerjea SK. Miasmatic prescribing its philosophy, diagnostic classifications, clinical tips, miasmatic repertory, miasmatic weightage of medicines and case illustrations. $7^{\text {th }}$ impression edition; New Delhi; B. Jain Publishers (P) Ltd 2017, 189, 191, 204, 227, 250, 214.

9. Allen HC. Keynotes and Characteristics with Comparisons of Some of the Leading Remedies of the Materia Medica with Bowel Nosodes $8^{\text {th }}$ edition published by B Jain Publishers (P) Ltd. New Delhi 2002, 204, 205, 206.

10. Dey SP. Essentials of Principles and Practice of Homoeopathy, enlarged third edition, published by Dr. Mrs. Sabita Rani Dey, Kolkata-700091 2005, 248, 251.

11. Phatak SR. A Concise Repertory of Homoeopathic
Medicines. $4^{\text {th }}$ ed., New Delhi: B. Jain Publishers (P) Ltd 2007, 89, 272.

12. Knerr Calvin B. Repertory of Hering's guiding Symptoms of our Materia Medica, Repr. ed. edition published by B Jain Publishers (P) Ltd. New Delhi 2002, 357.

13. Bhanja KC. Constitution: Drug pictures and treatment; Third Edition; Calcutta, National Homoeo Laboratory 1993, 234, 236, 237.

14. Kent JT. Repertory of the Homoeopathic Materia Medica ( $6^{\text {th }}$ American edition). 52 ${ }^{\text {nd }}$ impression New Delhi; B. Jain Publishers (P) Ltd; New Delhi 2014, 12, 64, 485, 486, 486, 530, 606, 1298, 1366, 427.

15. More CB, Bhavsar K, Varma S, Tailor M. Oral mucocele: A clinical and histopathological study. J Oral Maxillofac Pathol 2014;18(S1):72-7.

16. Bailey \& Love's Short practice of surgery edited by Charles V. Mann, R.C.G. Russell, Norman S. Williams, $2^{\text {nd }}$ reprinted edition, London, ELBS with Chapman \& Hall 1996, 1997, 440.

17. Chaitanya P, Praveen D, Reddy M. Mucocele on lower lip: A case series, Indian dermatology online journal 2017;8(3):205-207. 10.4103/idoj.IDOJ_151_16.

18. Jaikaria A, Thakur S. Mucocele: A case report with 24 months of follow-up, Int J Pedod Rehabil 2020;5(1):1315. 10.4103/ijpr.ijpr_14_19. 